\title{
Fatal Cervical Spine Injury Following a Bicycle Crash
}

\author{
Lars Uhrenholt ${ }^{1,2 *}$, Lene Warner Thorup Boel ${ }^{1,2}$, Asser Hedegaard Thomsen ${ }^{1}$
}

'Department of Forensic Medicine, Aarhus University, 8200 Aarhus, Denmark

2Paraclinical Imaging Studies Group (PIMAS), Aarhus University, 8200 Aarhus, Denmark

*E-mail: lu@forens.au.dk

\begin{abstract}
:
Spinal injury following direct loading of the head and neck is a rare sequel of bicycle crashes. Fatal head injuries following bicycle crashes have been described in great detail and safety measures such as bicycle helmets have been developed accordingly. Less frequently, however, potentially severe cervical spine injuries have been described. We present the case of a middle-aged female who sustained an ultimately fatal cervical spine injury following a collision with a car whilst biking wearing a helmet. We discuss the literature regarding the protective effects of bicycle helmets, the relevance to cervical spine injury and legislation on mandatory use of helmets for injury prevention.
\end{abstract}

Keywords:

fatal bicycle trauma, bicycle helmet, road traffic crash, cervical spine injury, medicolegal autopsy, post-mortem computed tomography

\section{INTRODUCTION}

Drivers of bicycles enjoy the freedom of outdoors activities beneficial for quality of life, improved health and overall well-being (1). There are great differences between countries in the utility of bikes as mode of urban transportation and sports activity. This influences the organization of national roads and traffic infrastructure in order to provide the safest possible conditions for biking. However, driving a bike is not without risk. The World Health Organization (WHO) recently published a global status on road safety estimating a total of 1.24 million traffic related fatalities per year worldwide of which 62.000 (5\%) were bicyclists (2). In Europe alone, around 2.000 cyclists were reported killed in traffic crashes in 2013 (3). Despite these daunting figures, the recent DaCoTA study, conducted by the European Road Safety Observatory (ERSO), reported a $38 \%$ reduction in the number of cyclists killed in road traffic crashes in the 20 European Union countries examined (EU-20a) during the period 2001-2010 (4), although a few countries have reported a minor increase since $2010(3 ; 5 ; 6)$. Despite the overall decrease in bicyclists' killed, the percentage of deaths on bicycles of the total number of people killed in the traffic has shown to increase in recent years (3;4;7-9). For example, in the Netherlands there has been an increase from 21\% in 2009 to 30\% in 2013, and in Denmark the percentage has more than doubled from $8 \%$ in 2009 to $17 \%$ in 2013 (Figure 1$)(4 ; 7 ; 9 ; 10)$. The most common serious (potentially fatal) injury from a bicycle trauma is head injury, representing up to $69 \%$ of all severe injuries in recent studies $(7 ; 11)$. Although potentially life threatening, cervical spine injuries following bicycle crashes are less frequent (approximately 5\%) and has therefore received less attention in traffic safety research (12;13). Wearing a helmet has been shown to prevent serious head injury (13-20), however its association with cervical spine injury is debatable $(13 ; 15 ; 16 ; 19 ; 21)$.

In this study, we present a case of a severe bicycle crash following which the bicyclist who used a helmet suffered no head injury but an ultimately fatal cervical spine injury.

\section{CASE REPORT}

A 43-year old female was the driver of a bicycle wearing a biking helmet. As she entered an intersection with a green traffic light she was hit from the side by a passenger car travelling at high-speed approximately $90 \mathrm{~km} /$ hour. The car attempted to brake shortly prior to impact. The victim was thrown onto the bonnet of the vehicle and fell to the ground. The vehicle sustained damage to the front bumper, scratches on the bonnet and a broken front window on the left side. The bicycle frame was crushed around the back wheel, and the front wheel was distorted. The bicycle helmet sustained significant damages on its backside. The female bicyclist suffered cardiac arrest at the scene but was successfully resuscitated and brought to the emergency department where a trauma computed tomography (CT) scanning revealed an unstable

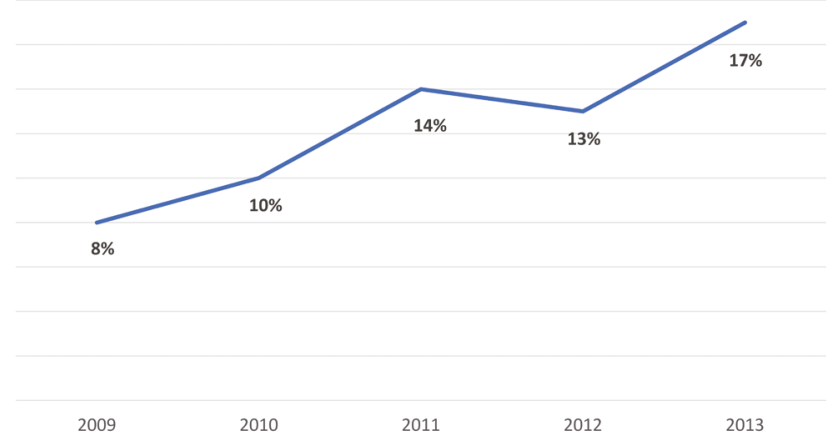

Figure 1 Percentage of bicycle fatalities of all road traffic fatalities in Denmark. The figure illustrates the gradual increase in bicyclists killed as a percentage of the total number of road traffic fatalities on Danish roads during the recent 5-year period 2009-2013 (10). 
fracture of C3-C4 with suspicion of spinal cord injury. An open fracture of the left shin was also noted. Stabilizing surgery was performed of the cervical spine fracture using a metal implant from the $3^{\text {rd }}$ to the $5^{\text {th }}$ cervical vertebrae under removal of the $4^{\text {th }}$ cervical vertebrae, and stabilization of the left shin fracture. Over the following days clinical examination revealed that the patient was paralyzed from the mid-cervical spine (tetraplegic). A magnetic resonance imaging (MRI) scan showed a blood clot in the spinal canal next to the fracture site, there was suspicion of a small subarachnoid bleeding in the right frontal region and an MR-angiogram showed reduced flow in the right vertebral artery possibly due to a dissection. Following the surgery the patient was alert and able to verbally communicate. Five days later a tracheotomy was performed for sustained mechanical ventilation which was followed by a short period of brachycardia (29 bpm), drop in blood pressure and loss of consciousness. Over the following 14 days she received antibiotic treatment for a urinary infection, she underwent repeated surgery of the left shin fracture and a stabilizing metal implant was surgically placed in the right upper arm due to an initially missed fracture. Throughout the hospitalization period she received a number of medications (Rapifen, Propofol, Cefuroxim, Fentanyl and Morphine/Contalgin). Twenty days after the road traffic crash she suddenly suffered a cardiac arrest and after unsuccessful resuscitation she died.

A medicolegal autopsy including a post-mortem CT scan was performed 5 days after death ( 25 days after the crash). The findings were in agreement with the antemortem information showing fracture- and osteosynthesis sequelae of C3-C5 (Figure 2 and 3), the right humerus

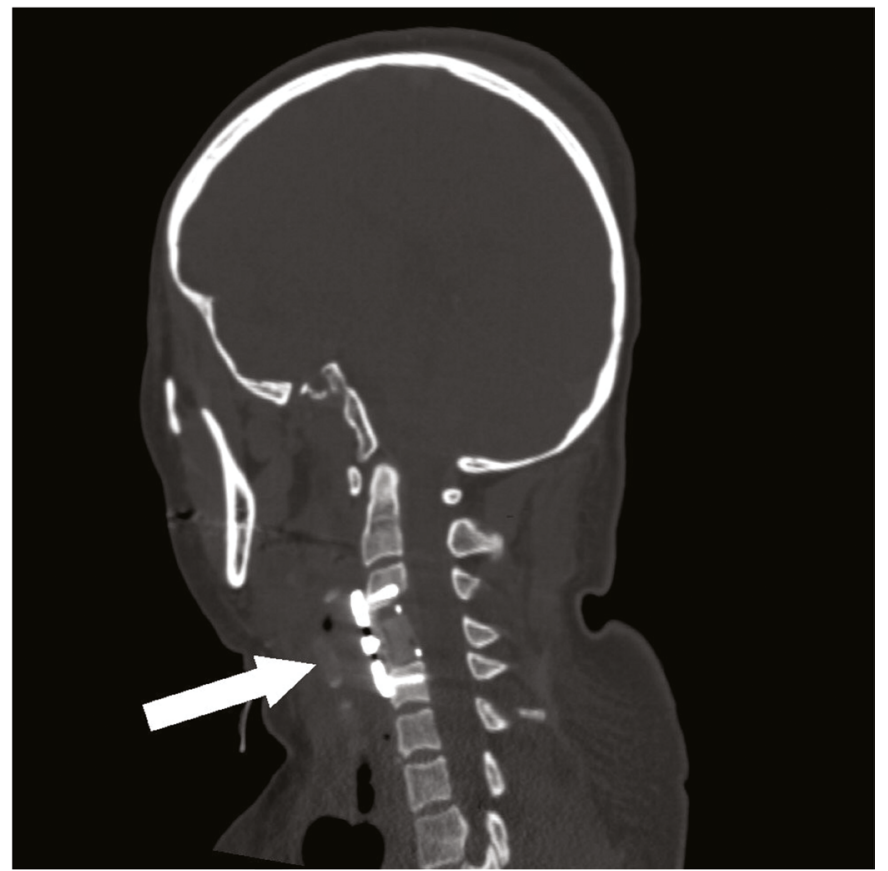

Figure 2 Post-mortem Computed Tomography scanning of the cervical spine. Post-mortem computed tomography scanning of the cervical spine of a bicyclist killed in a road traffic crash. The scan shows stabilizing osteosynthesis of C3-C5 (white arrow) following a cervical spine fracture (Siemens 64 multi-slice CT-scanner, using a slice thickness of $1.0 \mathrm{~mm}$, pitch $0.75,140 \mathrm{kVp}$ and $m A s$ adjusted for body and head size, reconstruction H60s sharp on Siemens workstation software). and left tibia. There was significant laceration and contusion of the spinal cord at the level of $\mathrm{C} 3$-C4 (Figure 4). There were external signs of contusion of the thorax, on both arms and the right leg. A tracheostomy had been performed and there were several rib fractures from attempted resuscitation. The post-mortem CT scan further revealed fracture of the coracoid process of the left scapula, the rear part of the left $7^{\text {th }}$ to $9^{\text {th }}$ rib, and of the $2^{\text {nd }}$ and $3^{\text {rd }}$ left metatarsal bones. On microscopy there were signs of healing bronchopneumonia. There was no evidence of cerebral contusion, bleeding or laceration. There were no skull fractures. The vertebral arteries were not examined in detail during autopsy. The cause of death was assumed to be heart failure secondary to fracture of the cervical spine with contusion and laceration of the cervical spinal cord.

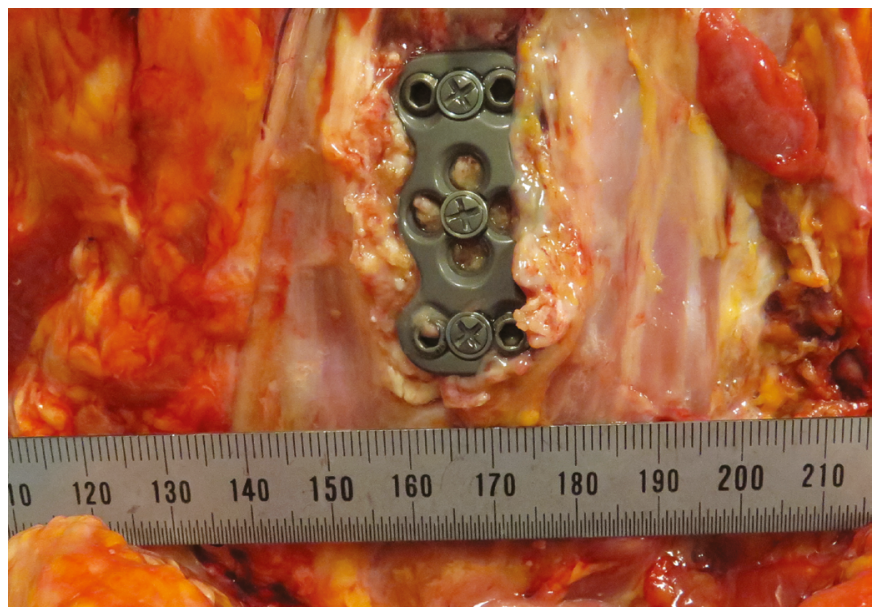

Figure 3 Cervical spine osteosynthesis of a cervical spine fracture following a fatal bicycle crash. Macroscopic evidence of stabilizing osteosynthesis material of $\mathrm{C} 3-\mathrm{C} 5$ following a cervical spine fracture viewed from the front during medicolegal autopsy.

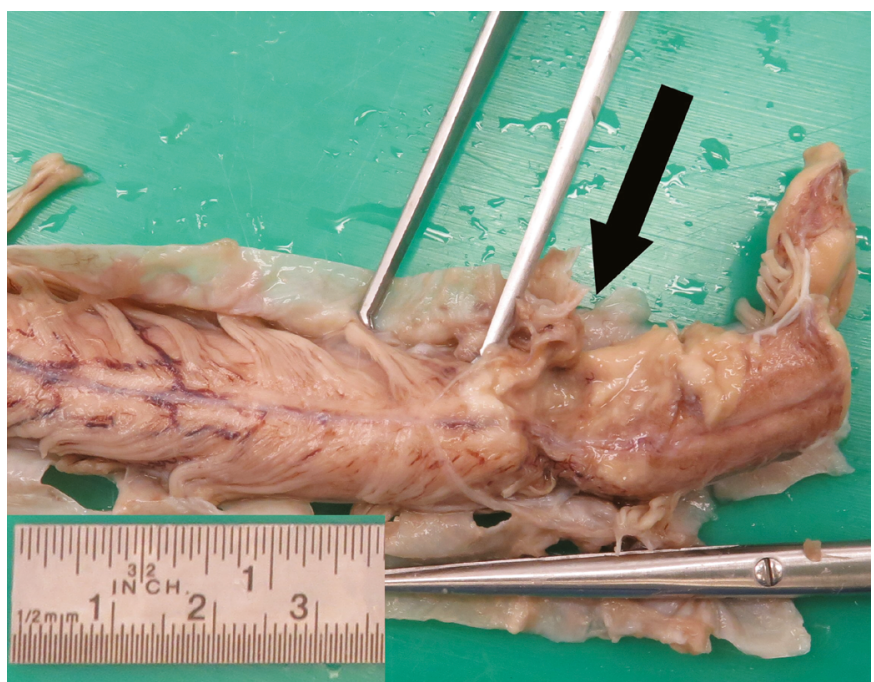

Figure 4 Spinal cord contusion and laceration following a fatal bicycle crash Macroscopic evidence of significant laceration and contusion of the spinal cord at the level of C3 -C4 (black arrow) viewed from the front during medicolegal autopsy. Note the ruler has been added to the image after calibration of size. 


\section{DISCUSSION}

This case report presents a middle-aged bicyclist who suffered a fatal cervical spine injury due to a collision with a passenger car driving with high speed. While wearing a bicycle helmet protecting her from head injury she suffered a fatal cervical spine fracture with spinal cord injury. This case report serves as an illustrative example of the inherent protective limitations provided by bicycle helmets in relation to cervical spine injury.

Bicyclists are vulnerable road users and the most common type of injurious bicycle crash in Denmark is a solo crash (approximately 80\%), i.e. not involving contact with other road users. However, in fatal bicycle crashes a vehicular counterpart is almost always present. Although collisions between bicycles and heavy goods vehicles (HGV), e.g. a truck or lorry, are far less common these have been responsible for up to $40 \%$ of bicyclists killed on Danish roads (12;22;23), although significantly lower in other countries (24). For this particular reason, right turning HGV's have been the focus for traffic safety campaigns in Denmark in recent years which has reduced the number of these types of collisions $(23 ; 25)$. Where bicycle helmets are likely to have limited influence on survivability on HGV collisions, they offer more relevant protection when considering the more common collision with passenger cars and solo crashes. The protective effect of bicycle helmets has been investigated in laboratory settings showing that helmets reduce the peak linear and angular acceleration forces acting on the head (26). These investigations contribute to the bicycle helmet standards that are now in place in most countries ensuring a comparable quality of the helmets (e.g. Europe EN 1078, US Consumer Product Safety Commission and the Australian/New Zealand 2063). Epidemiological studies have shown strong scientific evidence in favour of helmets reducing the severity of head and face injury and risk of death (13-19), with an estimated reduction of serious head injury of approximately $50 \%$ and fascial injury of approximately $25 \%$ $(16 ; 19)$. Although higher figures have been reported $(13 ; 15 ; 17)$, the sizes of these increased protective effects attributed to bicycle helmets have recently been questioned (16;27). Cervical spine injuries, including fractures and dislocations with or without spinal cord injury, are present in approximately $5 \%$ of the total number of injuries among severely affected bicyclists $(12 ; 13)$. Interestingly, cervical spine injuries following bicycle crashes are likely to occur irrespective of helmet use due to the multitude of force vectors acting on the neck in a crash. A meta-analysis by Elvik found that when analysed in isolation wearing a bicycle helmet appeared to increase the risk of cervical spine injury by approximately $25 \%$ (16). However, other studies have found no such association $(13 ; 15 ; 16 ; 21)$, and a more recent meta-analysis by Olivier and Creighton found no association between neck injury and helmet use (19). Irrespective of these findings, bicycle helmet may absorb/disperse some of an injurious loading and at the same time transfer some of that load to the cervical spine. Similarly, the cervical spine is at risk of direct impact as well as indirect transfer of force in the presence and absence of head impact, similar to a whiplash mechanism of injury (28). Hence, cervical spine injury may occur whether or not a helmet has been used and the risk of injury appears not to be associated $(13 ; 15 ; 16 ; 21)$. The current case report highlights this particular point. Although the deceased was hit by a passenger car at high-speed (approximately $90 \mathrm{~km} /$ hour) the helmet provided adequate protection to the head as no fractures could be identified in the skull and there was no evidence of cerebral injury. However, a serious cervical spine injury involving a fracture and spinal cord injury lead to the death of the victim. The question is - should a helmet be mandatory when riding a bike? Some countries already have legislated on this topic (e.g. Sweden and other European countries, Australia and the United States). However, the usage of bicycle helmets differs greatly among countries, e.g. Ireland (46\%), Sweden (37\%), Denmark (28\%), Germany (15\%), and Poland and Latvia 12\% (3;29), and appears to be irrespective of national bicycle wearing policies. For example, Latvia has mandatory use for children but scores low on wearing rates (3). Mandatory helmet use has not been clearly associated with changes in bicycle use (i.e. reduced biking), and legislation therefore does not seem to influence the general public health in any negative manner (20;30-33). Furthermore, there is strong scientific evidence that helmet use significantly reduce the number and severity of head injuries irrespective of the presence or absence of national legislation on helmet use (14-17;19;34;35). Similarly, there is no reason to assume that spinal injury risk is influenced by helmet use (19). Hence, ideally all bicyclists should wear a bicycle helmet. The protective effects of helmets could be further improved and possibly combined with airbag devices that cover/protect the cervical spine. A new airbag helmet from Sweden shows promising results in laboratory studies with a reduction of the head load resulting in significant reduced Head Injury Criterion (HIC) values. This indicates a reduced risk of skull fractures and concussion/brain injury. Furthermore, computer simulations of the maximum strain values in the brain is lower with an airbag helmet compared with any other standard helmet, and the shock absorption performance is almost three times better for the airbag helmet (36;37). However, as no scientific studies examining the efficiency on injury prevention of the airbag helmet on head and/or neck injuries in real world crashes have been published no conclusions can be made in this regard. Recent vehicular designs offer additional protection to the cyclist in case of collision with the vehicle through exterior airbags and bonnet improvements. Cultural and societal questions regarding acceptable manners of biking should be addressed as well, involving not only the behaviour of bicyclists on the roads but also the discussion of biking under the influence of alcohol and drugs $(5 ; 6 ; 35)$.

\section{CONCLUSIONS}

This case report of a fatal cervical spine injury following a severe bicycle crash serves to illustrate the point that bicycle helmets provide at best limited protection to the cervical spine during crashes. Although serious cervical spine injuries are rare after bicycle crashes, such injuries must be considered when examining victims of bicycle crashes. Helmet use must be strongly encouraged for all ages and at all times when biking as this significantly reduces the risk of serious head injury. 


\section{REFERENCES}

[1] Andersen LB, Schnohr P, Schroll M, Hein HO. All-cause mortality associated with physical activity during leisure time, work, sports, and cycling to work. Arch Intern Med 2000; 160(11):1621-1628.

[2] World Health Organization. Global status report on road safety 2013: supporting a decade of action. 2013. World Health Organization, Geneva,Switzerland.

[3] European Transport Safety Council. Making walking and cycling on Europe's roads safer. 2015. European Transport Safety Council, Brussels, Belgium.

[4] Candappa N, Thomas P, Yannis G, Broughton J, Brandstaetter C, Pace JF et al. Basic Fact Sheet "Cyclists". 2012. Deliverable D3.9 of the EC FP7 project DaCoTA., European Commision, Directorate-General for Mobility and Transport.

[5] Williams A. Bicyclist Safety. 2014. Governors Highway Safety Association, Washington DC, USA.

[6] Halpern LW. U.S. Bicyclist deaths in motor vehicle accidents increase dramatically. Am J Nurs 2015; 115(2):17.

[7] Weijermars W, Bos N, Stipdonk HL. Serious road injuries in the Netherlands dissected. Traffic Inj Prev 2016; 17(1):73-79.

[8] National Highway Traffic Safety Administration. NCSA Data Resource Website - Fatality Analysis Reporting System (FARS) - National Statistics. 2013. National Highway Traffic Safety Administration (NHTSA), Washington DC, USA. Accessed online october 6, 2015; www-fars.nhtsa.dot.gov/Main/index.aspx.

[9] Forsse A, Eskesen V, Springborg JB. Bicycle helmet prevents brain damage. Ugeskr Laeger 2015; 177(V10140560):2-5.

[10] Danmarks Statistik. UHELDK1: Tilskadekomne og dræbte i færdselsuheld efter område, personskade, indblandede transportmidler, alder og køn. 2015. Danmarks Statistik, Copenhagen. Accessed online June 30, 2015; www. statistikbanken.dk.

[11] Amoros E, Chiron M, Thelot B, Laumon B. The injury epidemiology of cyclists based on a road trauma registry. BMC Public Health 2011; 11:653.

[12] Møller H, Damm M, Laursen B. Ulykker i Danmark 1990-2009. 2012. Copenhagen, Denmark, Statens Institut for Folkesundhed, Syddansk Universitet.

[13] Amoros E, Chiron M, Martin JL, Thelot B, Laumon B. Bicycle helmet wearing and the risk of head, face, and neck injury: a French case--control study based on a road trauma registry. Inj Prev 2012; 18(1):27-32.

[14] Institute of Transport Economics. Trafikksikkerhetshåndboken. 2012. Oslo, Norway, Institute of Transport Economics.

[15] Attewell RG, Glase K, McFadden M. Bicycle helmet efficacy: a meta-analysis. Accid Anal Prev 2001; 33(3):345-352.

[16] Elvik R. Corrigendum to: "Publication bias and time-trend bias in meta-analysis of bicycle helmet efficacy: a re-analysis of Attewell, Glase and McFadden, 2001" [Accid. Anal. Prev. 43 (2011) 1245-1251]. Accid Anal Prev 2013; 60:245-253.

[17] Bambach MR, Mitchell RJ, Grzebieta RH, Olivier J. The effectiveness of helmets in bicycle collisions with motor vehicles: a case-control study. Accid Anal Prev 2013; 53:78-88.

[18] Persaud N, Coleman E, Zwolakowski D, Lauwers B, Cass D. Nonuse of bicycle helmets and risk of fatal head injury: a proportional mortality, case-control study. CMAJ 2012; 184(17):E921-E923.
[19] Olivier J, Creighton P. Bicycle injuries and helmet use: a systematic review and metaanalysis. Int J Epidemiol 2016;([Epub ehead of print] 10.1093/ije/dyw153 [doi]).

[20] Kett P, Rivara F, Gomez A, Kirk AP, Yantsides C. The Effect of an All-Ages Bicycle Helmet Law on Bicycle-Related Trauma. J Community Health 2016; 41(6):11601166.

[21] Rivara FP, Thompson DC, Thompson RS. Epidemiology of bicycle injuries and risk factors for serious injury. Inj Prev 1997; 3(2):110-114.

[22] Munkholm J, Thomsen AH, Lynnerup N. [Fatal bicycle accidents involving right turning heavy goods vehicles--forensic pathological findings]. Ugeskr Laeger 2007; 169(3):232-235.

[23] Havarikommissionen for Vejtrafikulykker. Ulykker mellem højresvingende lastbiler og ligeudkørende cyklister. 2006. Copenhagen, Denmark, Havarikommissionen for Vejtrafikulykker.

[24] Trafikstyrelsen, Vejdirektoratet, Rigspolitiet. Rejserapport - Beskrivelse af udenlandske erfaringer om forebyggelse af højresvingsulykker mellem lastbiler og cyklister. 2014. Transport- og Bygningsministeriet, København, Danmark.

[25] Trafikstyrelsen, Vejdirektoratet, Rigspolitiet. Strategi for forebyggelse af højresvingsulykker. 2014. Transport- og Bygningsministeriet, København, Danmark.

[26] McIntosh AS, Lai A, Schilter E. Bicycle helmets: head impact dynamics in helmeted and unhelmeted oblique impact tests. Traffic Inj Prev 2013; 14(5):501-508.

[27] Macpherson A, Spinks A. Bicycle helmet legislation for the uptake of helmet use and prevention of head injuries. Cochrane Database Syst Rev 2008;(3):CD005401.

[28] Siegmund GP. What occupant kinematics and neuromuscular responses tell us about whiplash injury. Spine (Phila Pa 1976 ) 2011; 36(25 Suppl):S175-S179.

[29] Jensen JS. Hjelmrapport - Brug af hjelm 2013. 2014. Copenhagen, Denmark, Rådet for Sikker Trafik.

[30] Robinson DL. No clear evidence from countries that have enforced the wearing of helmets. BMJ 2006; 332:722-725.

[31] Finch CF, Neiger D. Bicycle use and helmet wearing rates in Melbourne, 1987 to 1992: The influence of the helmet wearing law. 45. 1993. Monash University Accident Research Centre.

[32] de Jong P. The health impact of mandatory bicycle helmet laws. Risk Analysis 2012; 32(5):782-790.

[33] Dennis J, Potter B, Ramsay T, Zarychanski R. The effects of provincial bicycle helmet legislation on helmet use and bicycle ridership in Canada. Inj Prev 2010; 16(4):219-224.

[34] Hagel B, Macpherson A, Rivara FP, Pless B. Arguments against helmet legislation are flawed. BMJ 2006; 332:725-726.

[35] Davidson JA. Epidemiology and outcome of bicycle injuries presenting to an emergency department in the United Kingdom. Eur J Emerg Med 2005; 12(1):2429.

[36] Stigson H, Kullgren A. Folksam's bicycle helmet test 2015. 2015. Folksam, Sweden.

[37] Kurt M, Laksari K, Kuo C, Grant GA, Camarillo DB. Modeling and Optimization of Airbag Helmets for Preventing Head Injuries in Bicycling. Ann Biomed Eng 2017; 45(4):1148-1160. 